\title{
BMJ Open Effectiveness of rehabilitation interventions on the secondary consequences of surviving a cardiac arrest: a systematic review and meta- analysis
}

Vicky L Joshi (1D , ${ }^{1}$ Jan Christensen, ${ }^{2}$ Esben Lejsgaard, ${ }^{1}$ Rod S Taylor, ${ }^{3}$ Ann Dorthe Zwisler, ${ }^{1}$ Lars $\mathrm{H}$ Tang ${ }^{4,5}$

To cite: Joshi VL, Christensen J, Lejsgaard E, et al. Effectiveness of rehabilitation interventions on the secondary consequences of surviving a cardiac arrest: a systematic review and meta-analysis. BMJ Open 2021;11:e047251. doi:10.1136/ bmjopen-2020-047251

- Prepublication history and additional supplemental material for this paper are available online. To view these files, please visit the journal online. (http://dx.doi.org/10.1136/ bmjopen-2020-047251).

Received 24 November 2020 Accepted 29 July 2021

Check for updates

(C) Author(s) (or their employer(s)) 2021. Re-use permitted under CC BY-NC. No commercial re-use. See rights and permissions. Published by BMJ.

For numbered affiliations see end of article.

Correspondence to

Mrs Vicky L Joshi;

victoria.Iouise.joshi@rsyd.dk

\section{ABSTRACT}

Aim The aim of this systematic review was to assess the effectiveness of rehabilitation interventions on the secondary physical, neurological and psychological consequences of cardiac arrest (CA) for adult survivors. Methods A literature search of electronic databases (MEDLINE, Allied and Complementary Medicine Database, Cumulative Index to Nursing and Allied Health Literature, Excerpta Medica database, Psychological Information Database, Web of Science and Cochrane Central Register of Controlled trials) was conducted for randomised controlled trials (RCTs) and observational studies up to 18 April 2021. The primary outcome was health-related quality of life (HRQLL) and main secondary outcome was neurological function with additional secondary outcomes being survival, rehospitalisation, safety (serious and nonserious adverse events), psychological well-being, fatigue, exercise capacity and physical capacity. Two authors independently screened studies for eligibility, extracted data and assessed risk of bias.

Results Three RCTs and 11 observational studies were included (total 721 participants). Study duration ranged from 8 weeks to 2 years. Pooled data from two RCTs showed low-quality evidence for no effect on physical HRQoL (standardised mean difference (SMD) 0.19, (95\% Cl: -0.09 to 0.47$)$ ) and no effect on mental HRQOL (SMD 0.27 (95\% Cl: -0.01 to 0.55$)$ ).

Regarding secondary outcomes, very low-quality evidence was found for improvement in neurological function associated with inpatient rehabilitation for $\mathrm{CA}$ survivors with acquired brain injury (SMD $0.71,(95 \% \mathrm{Cl}$ : 0.45 to 0.96$)$ ) from five observational studies. Two small observational studies found exercise-based rehabilitation interventions to be safe for CA survivors, reporting no serious or non-serious events.

Conclusions Given the overall low quality of evidence, this review cannot determine the effectiveness of rehabilitation interventions for CA survivors on HRQoL, neurological function or other included outcomes, and recommend further high-quality studies be conducted. In the interim, existing clinical guidelines on rehabilitation provision after CA should be followed to meet the high burden of secondary consequences suffered by CA survivors.
Strengths and limitations of this study

- This is the first systematic review and meta-analysis to assess the effectiveness of rehabilitation interventions for cardiac arrest (CA) survivors.

- Comprehensive literature searches were conducted with the inclusion of both randomised controlled trial and observational studies, and a wide range of outcomes relevant to CA survivors.

- High heterogeneity in intervention design and outcome measures limited the possibility for metaanalysis of study results.

- Quality of evidence was generally low with the majority of studies having small or very small sample sizes and insufficient description of the rehabilitation interventions.

PROSPERO registration number CRD42018110129.

\section{INTRODUCTION}

The number of people surviving a cardiac arrest (CA) to hospital discharge is increasing due to improvements in postcardiac arrest systems of care. ${ }^{1}$ In the USA, survival to hospital discharge is now $11.4 \%$ translating to 70000 new CA survivors each year with this number expected to increase. ${ }^{12}$ However, after survival, multiple research studies have documented the secondary physical, neurological and psychological consequences for CA survivors. ${ }^{13-6}$ Rehabilitation helps people to achieve and maintain optimum functioning in interaction with their environments. Rehabilitation interventions have shown benefits for the secondary consequences of brain injury or cardiac events ${ }^{89}$ indicating the same may be true for CA survivors. Rehabilitation after surviving a CA is recommended in consensus-based international clinical guidelines ${ }^{11011}$ but, to date, there has not been a 
systematic assessment of the effectiveness of rehabilitation interventions for CA survivors. ${ }^{12}$ In previous consensus building research with survivors, relatives and clinicians, quality of life and neurological function were identified as important outcomes after CA. ${ }^{413}$

The aim of this systematic review and meta-analysis was to assess the effectiveness of rehabilitation interventions for adult CA survivors. The primary outcome was healthrelated quality of life (HRQoL) and main secondary outcome was neurological function. Additional secondary outcomes were survival, rehospitalisation, safety (serious and non-serious adverse events), psychological well-being, fatigue, exercise capacity and physical capacity.

\section{METHODS}

\section{Protocol and registration}

This systematic review and meta-analysis is reported according to the Preferred Reporting Items for Systematic Reviews and Meta-Analyses guidelines (online supplemental file 1). ${ }^{14}$

\section{Eligibility criteria}

Studies using randomised controlled trials (RCTs) using individual or cluster randomisation in a parallel or crossover design, pilot studies, non-RCTs and prospective/ retrospective observational studies were included. Studies using a case series or case report design were excluded.

The parameters for the systematic review were defined using the Population, Intervention Comparator, Outcome (PICO) framework. The question being: What is the effectiveness among adult ( $\geq 18$ years) CA survivors $(\mathrm{P})$, of rehabilitation interventions (I) on HRQoL and neurological function $(\mathrm{O})$ ? Comparator was defined as no treatment, active control, usual care, additional intervention or no comparator $(\mathrm{C})$. No restriction on publication date, language or length of follow-up was made.

Studies that included both CA survivors and people with cardiac disease without CA were eligible for inclusion if subgroup data for CA survivors were presented or if these specific data could be obtained by contacting the study authors. If separate subgroup data for CA survivors could not be acquired, studies were eligible for inclusion if at least $50 \%$ of participants were CA survivors. Studies with mixed CA survivors and non-CA survivors acquired brain injury populations were treated in the same way.

Rehabilitation can be defined as: 'A set of measures that assist individuals, who experience or are likely to experience disability, to achieve and maintain optimum functioning in interaction with their environments'. ${ }^{7}$ To align with this broad definition of rehabilitation and ensure inclusion of all possible rehabilitation interventions, interventions were included if they were not primarily pharmacologically or surgically based or involved invasive technology. Interventions in the emergency room or critical care unit setting were excluded.

The primary outcome was HRQoL. HRQoL outcome measures could include generic or disease-specific patient-reported outcome measures and could be either a single item or multi-item outcome measure. The main secondary outcome was neurological function, defined as measuring the level of disability after a neurological event. Measures may primarily test cognitive ability or may combine cognitive and physical ability hence measuring global disability. Additional secondary outcomes were survival, rehospitalisation, safety (serious and non-serious adverse events), psychological well-being, fatigue, exercise capacity and physical capacity. Measures may be patient reported, clinician reported, observer reported or performance based. The primary and main secondary outcomes were chosen as, alongside survival, HRQoL and neurological function have been identified as important core outcome domains after CA by survivors, relatives and clinicians. ${ }^{413}$ Choice of secondary outcomes was informed by existing evidence on the secondary consequences of $\mathrm{CA}^{1356}$ and inspired by outcomes in previous systematic reviews on rehabilitation with other cardiac disease populations. ${ }^{815}$

\section{Information sources}

Preliminary searches were conducted to identify relevant search terms and subject headings. The final systematic search for eligible studies was conducted in the online databases: The National Library of Medicine (MEDLINE), Allied and Complementary Medicine Database, Cumulative Index to Nursing and Allied Health Literature, Excerpta Medica database, Psychological Information Database, Web of Science, Cochrane Database of Systematic Reviews and Cochrane Central Register of Controlled trials were initially searched on 2 December 2019 and updated on 18 April 2021. Abstracts from the "postcardiac arrest conferences' 2013-2019 were hand searched, and bibliographies of articles included at the full-text stage were reviewed to identify possible additional studies. Ongoing trials were identified by searching clinical trial registries (International Standard Randomised Controlled Trial Number, WHO International Clinical Trials Registry Platform and ClinicalTrials.gov).

\section{Searches}

The search matrix consisted of a combination of keywords and synonyms for: (1) CA and (2) non-pharmacological/ surgical/invasive technology rehabilitation interventions. The complete search strategy and detailed search matrix is outlined in online supplemental table 1 .

\section{Study selection}

Using the technology platform Covidence, two authors (VLJ and EL) independently screened all identified studies, first by title and abstract, and then after reading the full-text articles. First and last authors of studies were contacted where full-text articles were unavailable or CA survivors subgroup data were required. Any disagreements in the screening process were discussed between the two authors and if necessary a third author was consulted (JC). 


\section{Data collection process}

Data were extracted from the included studies independently by two review authors (VLJ and LHT) using a predefined standardised data extraction form. Any inconsistencies between authors in the data extraction process were resolved by discussion and if necessary a third author was consulted (JC).

\section{Data items}

Extracted data items included: study characteristics (author, year of publication, country, number of groups, number of participants, inclusion and exclusion criteria, setting, method of recruitment, aim of study, study design, length of study), characteristics of participants (mean age, gender, ethnicity, cause of CA, and comorbidities), description of intervention (duration, timing after CA, provider of intervention, description of control if relevant), theory or mechanism of intervention, outcomes (measured at baseline, hospital discharge, 3 months and final follow-up point and, if present, mortality, rehospitalisation, serious and non-serious adverse events) and results (sample sizes, baseline and all follow-up points, mean, estimate of effect, CI, SD, p value).

\section{Risk of bias in individual studies}

Two researchers independently assessed risk of bias for the included studies. RCTs were assessed using the RoB 2: a revised tool for assessing risk of bias in randomised trials, ${ }^{16}$ and observational studies were assessed using the National Institutes of Health Quality Assessment Tool for Before-After (Pre-Post) Studies With No Control Group. ${ }^{17}$

\section{Summary measures}

For continuous data, the effectiveness of the rehabilitation interventions was expressed either as mean difference (MD) or as standardised MD (SMD) with 95\% CI. For time-to-event outcomes (survival, rehospitalisation), hazard ratios were pooled if presented.

\section{Synthesis of results}

If more than one study reported an outcome related to the outcomes of interest, the clinical heterogeneity (similarity in CA survivors population, rehabilitation interventions and outcomes) was assessed. If studies were considered clinically comparable, data were pooled using a random effects meta-analysis. SMD was calculated where the same outcome was reported but using different measurement tools with values of $0.2,0.5$ and 0.8 interpreted as small, medium and large effect sizes, respectively. Separate analyses were conducted for RCTs and observational studies. Study heterogeneity was examined using the Cochran $Q$ test and quantified with $\mathrm{I}^{2}$ statistic (statistical heterogeneity indicated by $\chi^{2}$ test, $\mathrm{p}<0.10$ and an $\mathrm{I}^{2}$ statistic $>50 \%$ ). All analyses were conducted using STATA V.16 (StataCrop) statistical software.

Results from the Short Form Health Survey (SF-36 or SF-12) can be reported as either two component scores, (physical/mental) or as eight subscales. To allow synthesis of results, where results were reported as the eight

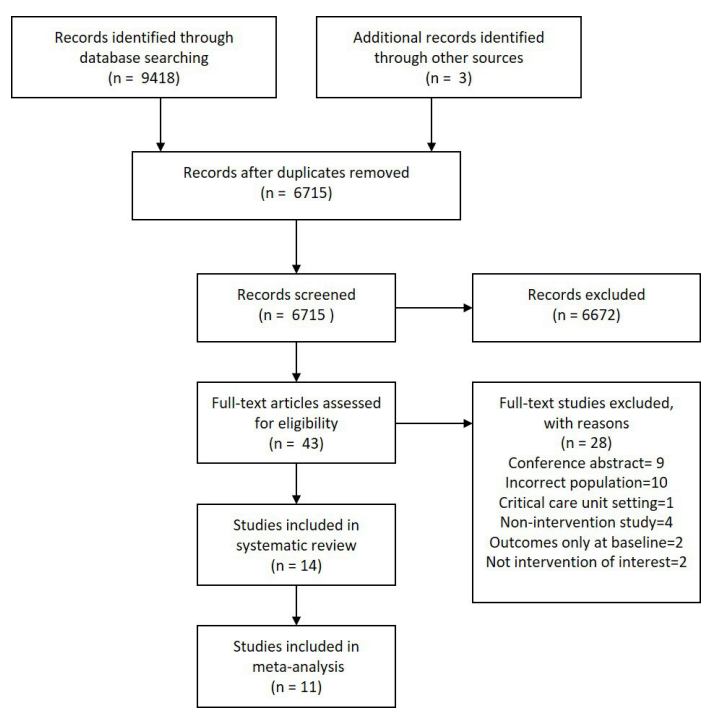

Figure 1 Preferred Reporting Items for Systematic Reviews and Meta-analyses flow diagram describing study selection.

subscales they were transformed into the two component scores following the method used by Matcham et $a l^{18}$

\section{Risk of bias and quality of evidence across studies}

Grades of Recommendation, Assessment, Development and Evaluation system (GRADE) ${ }^{19}$ was used to assess the overall quality of evidence across studies separately for the primary and main secondary study outcomes.

\section{Additional analyses}

If possible, subgroup and stratified analyses, metaregression and assessment of small study bias will be investigated as prespecified in the protocol (online supplemental file 1).

\section{Patient and public involvement}

The need for the systematic review of rehabilitation interventions, and identification of important outcomes for the systematic review, were developed from a patient and public involvement event involving survivors, relatives and clinicians. ${ }^{13}$

\section{RESULTS}

\section{Study selection}

The search identified 6715 unique articles. After screening titles and abstracts, 43 full-text articles were screened, of which 14 studies were included for analysis. ${ }^{20-34}$ Studies excluded at the full-text stage are listed with reasons in online supplemental table 2 . Figure 1 presents the study flow chart and reasons for exclusion in the full text screening. Two registered ongoing trials were identified. $^{3536}$

\section{Study characteristics}

Study characteristics of the 14 included studies are described in online supplemental table 1.

Three RCTs (total 393 participants) and 11 observational studies (total 328 participants) were included. Nine studies 
A

\begin{tabular}{|l|l|l|l|l|l|l|}
\cline { 2 - 7 } \multicolumn{1}{c|}{} & \multicolumn{5}{c|}{ Risk of bias domains } \\
\hline $\begin{array}{l}\text { Study } \\
\text { author, year }\end{array}$ & $\begin{array}{l}\text { Randomization } \\
\text { process }\end{array}$ & $\begin{array}{l}\text { Deviations } \\
\text { from intended } \\
\text { interventions }\end{array}$ & $\begin{array}{l}\text { Missing } \\
\text { outcome data }\end{array}$ & $\begin{array}{l}\text { Measurement } \\
\text { of the outcome }\end{array}$ & $\begin{array}{l}\text { Selection of the } \\
\text { reported } \\
\text { results }\end{array}$ & $\begin{array}{l}\text { Overall risk of } \\
\text { bias }\end{array}$ \\
\hline Cowan, 2001 & - & $?$ & - & $?$ & $?$ & - \\
\hline Dougherty, 2004 & + & $?$ & + & - & $?$ & - \\
\hline Moulaert, 2015 & + & + & + & + & $?$ & $?$ \\
\hline
\end{tabular}

+ = Low risk; ? = Some concerns; - = High risk

B

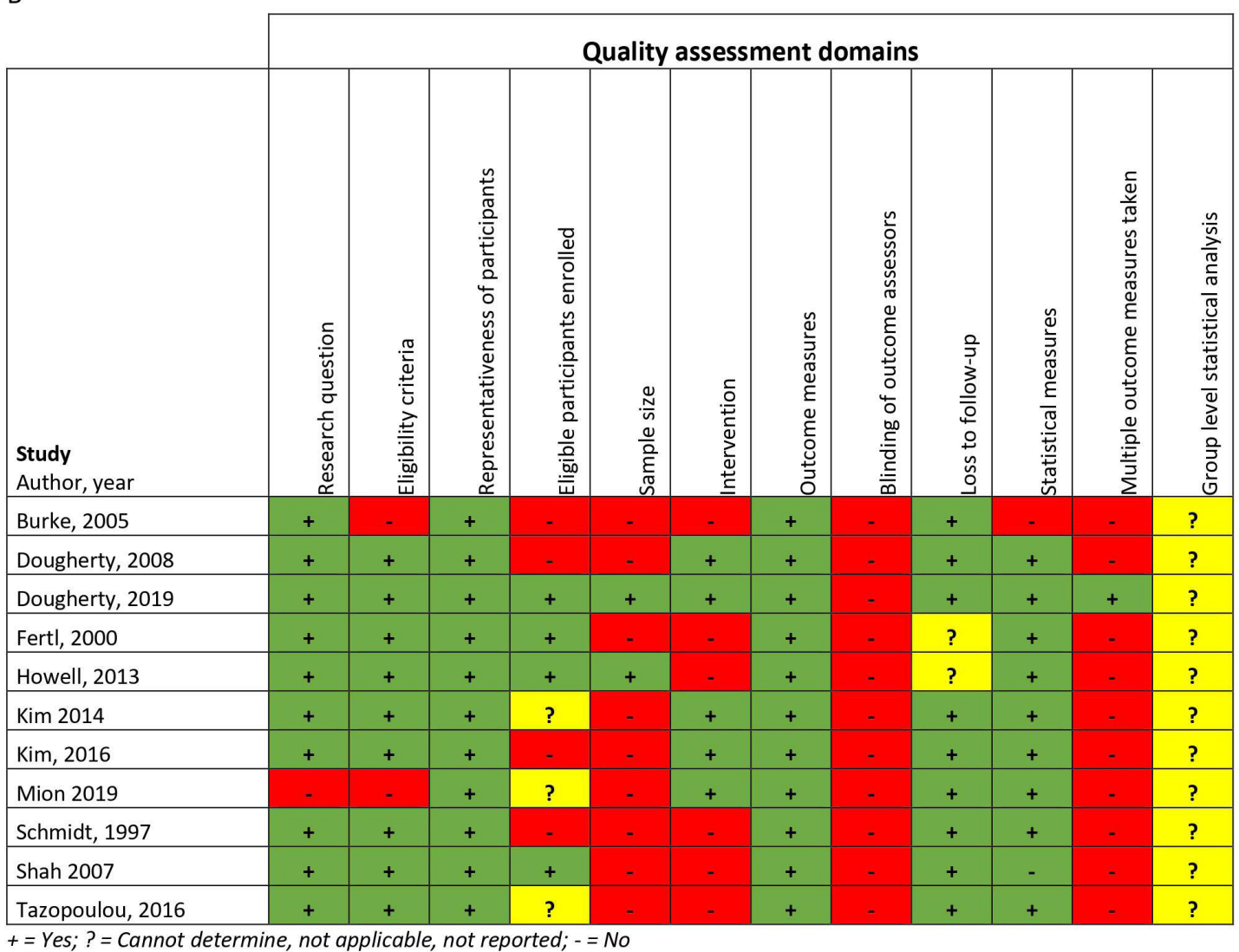

Figure 2 Quality assessment and risk of bias, review authors judgements about quality assessment and risk of bias for each included study. (A) Summary based on 'RoB 2: a revised tool for assessing risk of bias in randomised trials'. (B) Summary based on 'Quality Assessment Tool for Before-After (Pre-Post) Studies With No Control Group'.

investigated outpatient or community-based rehabilitation interventions of which three were RCTs. Five studies investigated inpatient rehabilitation for acquired brain injury, all were observational studies. Considering the very different CA survivor populations and intervention settings, the results for outpatient or community-based rehabilitation studies and inpatient rehabilitation for acquired brain injury are presented separately. Study follow-up period ranged from 1 to 24 months. One study ${ }^{25}$ had CA survivors in both arms of the RCT receiving the same intervention, hence, data from both arms were combined and treated as one observational study (data obtained from study authors).

\section{Risk of bias within studies}

Risk of bias assessments are summarised in figure 2A,B. Of the three included RCTs, ${ }^{21-23} 31$ Moulaert $e t a \ell^{11}$ was assessed as having 'some concerns' and the two other studies $^{21-23}$ were assessed having a 'high risk' of bias in the overall risk of bias assessment. Ten of the 11 observational studies had multiple high risk of bias domains.

\section{Results of individual studies}

A summary of the results of the individual studies is reported in online supplemental table 1 .

\section{Synthesis of results}

Health-related quality of life

In total, two $\mathrm{RCTs}^{22} 23 \quad 31$ and four observational studies $^{2425} 3034$ measured HRQoL.

HRQoL meta-analysis

Two RCTs ${ }^{22} 231$ evaluated the effectiveness of a rehabilitation intervention compared with standard care. The 
A

\begin{tabular}{|c|c|c|c|c|c|c|c|c|c|}
\hline \multirow[b]{2}{*}{ Study } & \multicolumn{3}{|c|}{ Intervention } & \multicolumn{3}{|c|}{ Control } & \multirow{2}{*}{ Standardised mean difference } & \multirow{2}{*}{$\begin{array}{l}\text { Hedges's g } \\
\text { with } 95 \% \mathrm{Cl}\end{array}$} & \multirow{2}{*}{$\begin{array}{c}\text { Weight } \\
(\%)\end{array}$} \\
\hline & $\mathrm{N}$ & Mean & SD & $\mathrm{N}$ & Mean & SD & & & \\
\hline Dougherty, 2004 & 32 & 42.91 & 10.11 & 22 & 42.81 & 10.72 & & $0.01[-0.53,0.54]$ & 27.33 \\
\hline Moulaert, 2015 & 76 & 74.04 & 25.03 & 67 & 67.34 & 27.37 & & $0.25[-0.07,0.58]$ & 72.67 \\
\hline \multicolumn{8}{|l|}{ Overall } & $0.19[-0.09,0.47]$ & \\
\hline \multicolumn{10}{|c|}{ Heterogeneity: $\mathrm{T}^{2}=0.00, \mathrm{I}^{2}=0.00 \%, \mathrm{H}^{2}=1.00$} \\
\hline \multicolumn{10}{|c|}{ Test of $\theta_{i}=\theta_{j}: Q(1)=0.59, p=0.44$} \\
\hline \multicolumn{10}{|c|}{ Test of $\theta=0: z=1.32, p=0.19$} \\
\hline Random effects $m$ & del & & & & & -.75 & $\begin{array}{lllll}-.5 & -.25 & 0 & .25 & .5\end{array}$ & & \\
\hline
\end{tabular}

B

\begin{tabular}{|c|c|c|c|c|c|c|c|c|c|}
\hline \multirow[b]{2}{*}{ Study } & \multicolumn{3}{|c|}{ Intervention } & \multicolumn{3}{|c|}{ Control } & \multirow[b]{2}{*}{ Standardised mean difference } & \multirow{2}{*}{$\begin{array}{l}\text { Hedges's g } \\
\text { with } 95 \% \mathrm{Cl}\end{array}$} & \multirow{2}{*}{$\begin{array}{c}\text { Weight } \\
(\%)\end{array}$} \\
\hline & $\mathrm{N}$ & Mean & SD & $\mathrm{N}$ & Mean & SD & & & \\
\hline Dougherty, 2004 & 32 & 54.3 & 7.56 & 22 & 53.65 & 8.3 & & $0.08[-0.45,0.62]$ & 27.44 \\
\hline Moulaert, 2015 & 76 & 78.25 & 14.78 & 67 & 72.76 & 17.27 & & $0.34[0.01,0.67]$ & 72.56 \\
\hline \multicolumn{7}{|l|}{ Overall } & & $0.27[-0.01,0.55]$ & \\
\hline \multicolumn{10}{|c|}{ Heterogeneity: $\mathrm{T}^{2}=0.00, \mathrm{I}^{2}=0.00 \%, \mathrm{H}^{2}=1.00$} \\
\hline \multicolumn{10}{|c|}{ Test of $\theta_{i}=\theta_{j}: Q(1)=0.66, p=0.42$} \\
\hline \multicolumn{10}{|c|}{ Test of $\theta=0: z=1.89, p=0.06$} \\
\hline Random effects $m$ & del & & & & & -.75 & $\begin{array}{lllllll}-.5 & -.25 & 0 & .25 & .5 & .7\end{array}$ & & \\
\hline
\end{tabular}

Figure 3 Forest plots for outpatient/community-based rehabilitation for cardiac arrest survivors compared with standard intervention, effect on health-related quality of life as measured by SF-12 or SF-36 (Short Form Health Survey) at 12 months follow-up. (A) Physical Component Score, (B) Mental Component Score

random effects meta-analyses showed from baseline to 12 months follow-up, no statistically significant effectiveness of rehabilitation interventions in physical HRQoL, overall SMD 0.19, (95\% CI: -0.09 to $0.47, \mathrm{p}=0.19$ ), $\mathrm{I}^{2}=00.0 \%$ or mental HRQoL, overall SMD 0.27 , (95\% CI: -0.01 to $0.55, \mathrm{p}=0.06$ ), $\mathrm{I}^{2}=0.00 \%$ (figure $3 \mathrm{~A}, \mathrm{~B}$ ).

Two observational studies ${ }^{25} 30$ could be pooled and a significant improvement in physical HRQoL was observed 6 months after baseline assessment, overall SMD 0.95 , (95\% CI: 0.64 to $1.27, \mathrm{p}<0.001), \mathrm{I}^{2}=0.00 \%, \mathrm{p}<0.001$ (figure 4A), however, no improvement in mental HRQoL was observed with an overall SMD $0.80,(95 \%$ CI: -0.45 to $2.05, p=0.21$ ), $I^{2}=90.17 \%$ (figure $4 B$ ).

HRQoL studies not included in meta-analysis

Due to clinical heterogeneity, two observational studies $^{24}{ }^{34}$ reporting on HRQoL were not included in the meta-analysis. One study, ${ }^{24}$ involving exercise-based rehabilitation, showed a non-significant increase in physical HRQoL at 8 weeks follow-up (44.33 points (SD 10.77 ) to 47.19 (SD 9.11), $\mathrm{p}=0.19$ ) and mental HRQoL (51.33 (SD 11.68) to 55.03 (SD 8.04), $\mathrm{p}=0.48$ ). A second observational study ${ }^{34}$ involving a community-based rehabilitation intervention for CA survivors with acquired brain injury showed a significant increase in HRQoL at 2 months follow-up (Quality of Life after Traumatic Brain Injury Satisfaction scale mean score, $82.25-89.95$ points, $\mathrm{p}=0.015$ ).
Neurological function

Neurological function was used as an outcome in one RCT $^{31}$ and six observational studies. $.^{20} 262732-34$

The $\mathrm{RCT}^{31}$ showed an outpatient rehabilitation intervention had no significant effectiveness in improving cognitive function on performance-based cognitive tests compared with standard care at any follow-up point.

Neurological function meta-analysis

Five observational studies ${ }^{20} 26273233$ were included in a meta-analysis. This showed rehabilitation significantly increased clinician-reported function, overall SMD 0.71, (95\% CI: 0.45 to $0.96, \mathrm{p}<0.001$ ), $\mathrm{I}^{2}=17.36 \%$, between admission and discharge for CA survivors with acquired brain injury (figure 5). Howell $e t a l^{27}$ was removed in a sensitivity analysis as the population were all in a vegetative or minimally conscious state with the lowest possible Functional Independence Measure (FIM) score of 18. This resulted in a larger overall SMD 0.89, (95\% CI: 0.56 to $1.22, \mathrm{p}<0.001$ ), $\mathrm{I}^{2}=0.00$ (online supplemental figure 1). In an analysis with the three observational studies $^{20} 3233$ using FIM as their outcome, rehabilitation interventions showed an improvement in total FIM, overall MD of 28.24 points (95\% CI: 16.33 to 40.15, $\mathrm{p}<0.001), \mathrm{I}^{2}=0.00 \%$, between admission and discharge (figure 6). 
A

\begin{tabular}{|c|c|c|c|c|c|c|c|c|c|c|}
\hline \multirow[b]{2}{*}{ Study } & \multicolumn{3}{|c|}{12 months } & \multirow[b]{2}{*}{$\mathrm{N}$} & \multicolumn{2}{|c|}{ Baseline } & \multirow{2}{*}{\multicolumn{2}{|c|}{ Standardised mean difference }} & \multirow{2}{*}{$\begin{array}{l}\text { Hedges's g } \\
\text { with } 95 \% \mathrm{Cl}\end{array}$} & \multirow{2}{*}{$\begin{array}{c}\text { Weight } \\
(\%)\end{array}$} \\
\hline & $\mathrm{N}$ & Mean & SD & & Mean & SD & & & & \\
\hline Dougherty, 2019 & 63 & 44.83 & 10.94 & 66 & 35.28 & 9.9 & & & $0.91[0.55,1.27]$ & 77.54 \\
\hline Mion, 2019 & 19 & 65.99 & 24.7 & 19 & 34.9 & 30.15 & & & $1.10[0.43,1.77]$ & 22.46 \\
\hline Overall & & & & & & & & & $0.95[0.64,1.27]$ & \\
\hline \multicolumn{11}{|c|}{ Heterogeneity: $\mathrm{T}^{2}=0.00, \mathrm{I}^{2}=0.00 \%, \mathrm{H}^{2}=1.00$} \\
\hline \multicolumn{11}{|c|}{ Test of $\theta_{i}=\theta_{i}: Q(1)=0.25, p=0.62$} \\
\hline \multicolumn{11}{|c|}{ Test of $\theta=0: z=5.89, p=0.00$} \\
\hline & & & & & & & $\begin{array}{ll}1 & -.5\end{array}$ & $\begin{array}{ll}1 & 1.5\end{array}$ & 2 & \\
\hline
\end{tabular}

Random effects model

Rehabilitation decreases physical HRQoL Rehabilitation increases physical HRQoL

B

\begin{tabular}{|c|c|c|c|c|c|c|c|c|c|}
\hline \multirow[b]{2}{*}{ Study } & \multicolumn{3}{|c|}{12 months } & \multicolumn{3}{|c|}{ Baseline } & \multirow{2}{*}{ Standardised mean difference } & \multirow{2}{*}{$\begin{array}{l}\text { Hedges's g } \\
\text { with } 95 \% \mathrm{Cl}\end{array}$} & \multirow{2}{*}{$\begin{array}{c}\text { Weight } \\
(\%)\end{array}$} \\
\hline & $\mathrm{N}$ & Mean & SD & $\mathrm{N}$ & Mean & SD & & & \\
\hline Dougherty, 2019 & 63 & 52.35 & 9.67 & 66 & 50.31 & 10.82 & & $0.20[-0.15,0.54]$ & 53.02 \\
\hline Mion, 2019 & 19 & 71.29 & 17.04 & 19 & 39.81 & 24.15 & & $1.47[0.77,2.18]$ & 46.98 \\
\hline \multicolumn{8}{|l|}{ Overall } & $0.80[-0.45,2.05]$ & \\
\hline \multicolumn{10}{|c|}{ Heterogeneity: $\mathrm{T}^{2}=0.74, \mathrm{I}^{2}=90.17 \%, \mathrm{H}^{2}=10.18$} \\
\hline \multicolumn{10}{|c|}{ Test of $\theta_{i}=\theta_{i}: Q(1)=10.18, p=0.00$} \\
\hline \multicolumn{10}{|c|}{ Test of $\theta=0: z=1.25, p=0.21$} \\
\hline and & 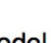 & & & & & & 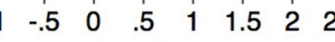 & .5 & \\
\hline
\end{tabular}

Rehabilitation decreases mental HRQoL Rehabilition increases mental HRQoL

Figure 4 Forest plots for outpatient/community-based rehabilitation for cardiac arrest survivors, effect on health-related quality of life (HRQLL) as measured by SF-12 or SF-36 (Short Form Health Survey) between baseline and 6 months follow-up (A) Physical Component Score, (B) Mental Component Score.

Neurological function data not included in meta-analysis

One observational study ${ }^{34}$ showed no significant change in neurological function after a community-based rehabilitation intervention for acquired brain injury. Further, Howell $e t a l^{27}$ found by discharge, 6.2\% of CA survivors with acquired brain injury in a vegetative or minimally conscious state achieved a good neurological functional outcome (defined as Glasgow Outcome Scale category 4-5). Cognition, specifically executive function, is the primary outcome in one ongoing trial, ${ }^{36}$ with results due in 2024.

\section{Survival}

Survival was used as an outcome in one RCT. ${ }^{21}$ The study found no statistically significant reduction in risk of all-cause mortality ( $62 \%$ risk reduction, $\mathrm{p}=0.13$, CI not stated). However, a statistically significant decrease in risk of cardiovascular death was found in favour of those who were allocated to the rehabilitation intervention $(86 \%$ risk reduction, $\mathrm{HR}=0.14 ; \mathrm{p}=0.03$, $\mathrm{CI}$ not stated) one death in the intervention group due to stroke, six out of seven deaths in control group due to CA.

Rehospitalisation

No study reported on rehospitalisation.

Safety (serious and non-serious adverse events)

Reported in two observational studies ${ }^{24}$ involving exercise-based rehabilitation. No serious or non-serious events were reported in either study. ${ }^{24} 28$

Psychological well-being

Psychological well-being was reported in one $\mathrm{RCT}^{31}$ and three observational studies. ${ }^{24}{ }^{25} 34$ No meta-analysis was

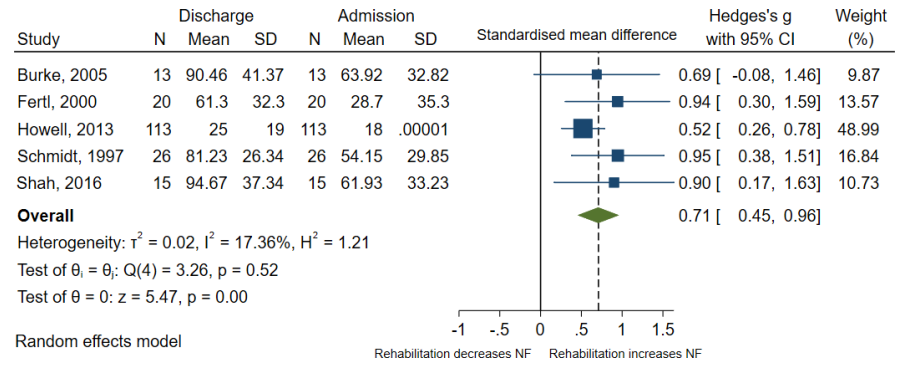

Figure 5 Forest plot for effect of inpatient rehabilitation on neurological function (NF) between admission and discharge. 


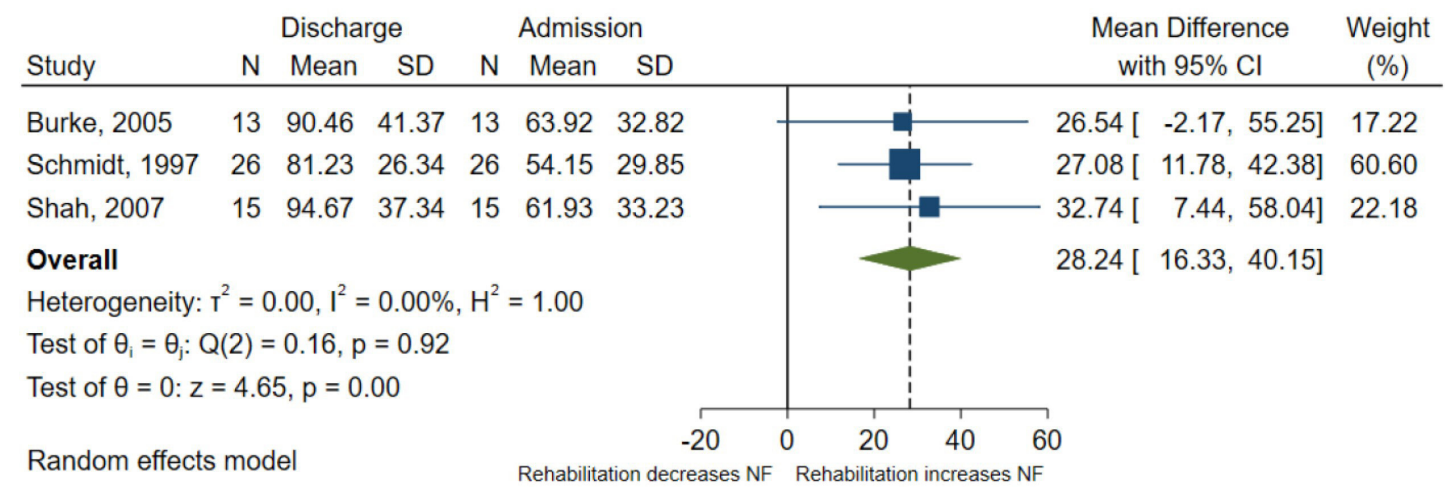

Figure 6 Forest plot for effect of inpatient rehabilitation for cardiac arrest survivors with acquired brain injury on neurological function (NF) between admission and discharge as measured by the Functional Independence Measure (scale: 18-126 points, with higher scores indicating better function).

possible due to clinical heterogeneity between studies. All studies used self-reported symptom measurements and not a medical diagnosis of psychological well-being.

The $\mathrm{RCT}^{31}$ found that education-based rehabilitation had a positive effect on total anxiety and depression $(\mathrm{p}=0.002)$ and anxiety subscale $(\mathrm{p}<0.001)$ compared with standard care at 1-year follow-up.

An observational study ${ }^{25}$ found that an education/ psychological support-based intervention had a reduction in anxiety (32.10 points (SD 11.03) to 28.57 (SD $9.65)$ ) and depression (5.46 points (SD 4.37) to 3.7 (SD $3.89)$ ) between baseline and 3 months. This was maintained at 12 months follow-up (28.87 (SD 10.62) and 3.36 (SD 4.29), respectively). An exercise-based rehabilitation intervention observational study ${ }^{24}$ found a non-significant reduction in anxiety (31.56 (SD 11.83) to 28.22 (SD 9.68), $\mathrm{p}=0.06$ ) and depression (11.00 ( $\mathrm{SD} 13.08$ ) to 9.22 ( $\mathrm{SD} 11.88$ ), $\mathrm{p}=0.46$ ) from baseline to 8 weeks follow-up. An observational study involving a community-based rehabilitation intervention for acquired brain injury showed no statistically significant change in anxiety or depression from baseline to 2 months follow-up. ${ }^{34}$

\section{Fatigue}

One observational study ${ }^{29}$ found between baseline and study end (3-5 weeks) of an energy conservation and problem solving therapy intervention, a significant decrease in self-reported total $(\mathrm{p}<0.001)$, physical $(\mathrm{p}=0.001)$ and cognitive $(\mathrm{p}=0.006)$ fatigue, with small to moderate effect sizes $(\mathrm{r}=0.23-0.25)$. Fatigue is the primary outcome in one ongoing trial, ${ }^{35}$ with results due in 2021.

\section{Exercise and physical capacity}

Reported in two observational studies. ${ }^{2428}$ Meta-analysis of the two studies found that an 8-week exercise-based rehabilitation intervention significantly increased exercise duration (MD $3.72 \mathrm{~min}$ (95\% CI: 0.49 to $6.95, \mathrm{p}=0.02$ ), $\mathrm{I}^{2}=42.61 \%$ but not exercise capacity, overall SMD 0.41, (95\% CI: $-0.23-1.04, \mathrm{p}=0.32$ ), $\mathrm{I}^{2}=0.00 \%$ (online supplemental figures 2 and 3 ).
Daily activity was reported in one observational study. ${ }^{28}$ Measured by RT3 accelerometer, it increased after an 8-week exercise-based rehabilitation intervention and continued to increase at 6-month follow-up (baseline 143.02 vector magnitude/minute $(\mathrm{vm} / \mathrm{min})(\mathrm{SD} 41.44)$, 8 weeks $230.0 \mathrm{vm} / \mathrm{min}$ (SD 121.78), 6 months $289.89 \mathrm{vm} /$ $\min (\mathrm{SD} 8.99), \mathrm{p}=0.17$ ).

\section{Risk of bias and quality of evidence across studies}

Quality of evidence (GRADE) for both the primary and main secondary outcomes, HRQoL and neurological function, was assessed as low for the RCTs and very low for the observational studies. Reasons for downgrading of evidence are described in the Summary of findings tables (online supplemental tables 3 and 4).

\section{Heterogeneity between studies}

Possibility for meta-analyses in this study was limited due to the heterogeneity in CA survivors populations, rehabilitation interventions and outcomes (online supplemental table 1).

\section{Additional analyses}

A priori, we planned several univariate meta-regression analyses ${ }^{37}$ subgroups analyses and investigation of small study bias (see protocol, online supplemental file 1). However, due to the limited number of included studies, all of these analyses were not conducted, as recommended in the Cochrane Handbook for Systematic Reviews of Interventions. $^{37}$

\section{DISCUSSION}

This study systematically investigated the effectiveness of rehabilitation interventions for CA survivors. Overall, quality of the body of evidence of these interventions is low or very low. Eleven of the 14 studies were observational and cannot determine the cause and effect of an intervention, but can only show the associated change in outcomes between one time point and another. The overall risk of bias of the three included RCTs ranged from 'some concerns' to 'high risk of bias' (figure 2A). 
Analysis of these RCTs showed no significant effect on HRQoL or neurological function with one RCT showing a positive effect on anxiety and depression (psychological well-being). The included observational studies suggested some associated positive change in outcomes, but the quality of the body of evidence was generally low (figure 2B) with the majority having small or very small sample sizes and insufficient description of the content of the rehabilitation interventions. Hence, all of the findings should be interpreted with caution as additional evidence is needed and could substantially impact the interpretation of the results.

The meta-analysis of RCTs found no significant effect for rehabilitation interventions on HRQoL. However, it should be noted that only two RCTs ${ }^{22} 231$ were included in this pooled analysis. The RCT by Moulaert et $a l^{31}$ taken on its own, reported a significant effect on HRQoL compared with control in three out of eight SF-36 domains (online supplemental table 1). Our findings on HRQoL, being mindful of the low number of included RCTs, are largely in agreement with an earlier systematic review of similar education-based rehabilitation interventions for patients with coronary heart disease. ${ }^{15}$ While the review authors found some evidence for greater HRQoL in some domain scores, overall, they found no definite evidence for better HRQoL after education in comparison to control.

A meta-analysis of two observational studies ${ }^{25} 30$ showed a significant associated increase in physical HRQoL. However, as is inherent to the study design, neither of the studies had a control group. From the control arms in the two RCTs, ${ }^{22} 2331$ we see that CA survivors receiving standard care also seem to improve over time (mean 12.8 points improvement in physical HRQol, online supplemental table 3). Thus, demonstrating the importance of using control group trial designs to determine the real effectiveness of rehabilitation interventions in this population.

Our main secondary outcome was neurological function. The only $\mathrm{RCT}^{31}$ to report neurological function found no effect of an outpatient intervention compared with usual care on cognitive function, however, Moulaert et $a l^{31}$ state that this was expected as the intervention did not include cognitive training. In the observational studies, inpatient rehabilitation was associated with improvements in neurological function for CA survivors with acquired brain injury (figure 5). Three of the studies $^{2032} 33$ reported total FIM (figure 6). The total FIM minimal clinically important difference (MCID) has not been described for CA survivors, but in patients who had a stroke, the MCID has been shown to be an improvement of $\geq 22$ points. ${ }^{38}$ Hence, the pooled mean improvement of 28.24 points found in this study would indicate inpatient rehabilitation provides a clinically significant improvement in neurological function for CA survivors. However, none of the studies had control arms, and all had several high risk of bias domains including insufficient description of intervention or small sample sizes. This review found very few studies aimed at improving neurological function including cognition for CA survivors. However, one ongoing RCT was found investigating a computerbased intervention to improve executive function with results due in $2024 .{ }^{36}$

Survival was only reported in one study ${ }^{21}$ that was judged to be of high risk of bias with missing data, therefore, no conclusions on the effect of rehabilitation on survival can be made. By definition, rehabilitation helps people to achieve and maintain optimum functioning in interaction with their environments. ${ }^{7}$ Hence, survival would not seem to be a primary outcome for rehabilitation for CA survivors.

Two small observational studies ${ }^{24}{ }^{28}$ reported exercisebased rehabilitation interventions as safe for CA survivors. The reporting of no serious or non-serious events is in agreement with earlier studies exploring safety during moderate or high intensity exercise training for people with cardiovascular disease ${ }^{39-41}$ or implantable cardioverter defibrillators. ${ }^{42}$ However, both included studies had very small populations (8 and 10 participants) and much larger study populations are needed to establish the safety of exercise for CA survivors.

Psychological interventions have been shown to reduce anxiety and depression in patients with coronary heart disease. ${ }^{43}$ The RCT by Moulaert $e t a \hat{l}^{31}$ found a reduction in total anxiety and depression although their intervention provided primarily education and screening for cognitive/emotional problems rather than psychological focused interventions. Education on the consequences of CA along with insight into their cognitive/emotional problems may have led to the participants' improved psychological state. Alternatively, participants in the intervention group could be referred for additional specialist support. However, we do not know what proportion of participants received additional specialist psychological support or how this may have influenced the results.

This is the first systematic review and meta-analysis to assess the effectiveness of rehabilitation interventions for CA survivors. Its strengths lie in the comprehensive literature searches, inclusion of both RCTs and observational studies, and the included wide range of outcomes relevant to CA survivors. Nevertheless, there are a number of limitations. In order to pool the HRQoL data, the SF-36 scores from two studies ${ }^{30}$ were transformed from subscales to component scores. Some overlap in physical/ mental domains between the eight subscales has been noted when using this transformation method. ${ }^{18}$ Therefore, transformed scores may not completely represent the original study results. ${ }^{18}$ We included two studies with populations of CA survivors and people with anoxic brain injury due to other causes $\left(45 \%{ }^{34}\right.$ and $42 \%^{32}$ participants with anoxic brain injury other causes) where CA survivors subgroup data were not available. Including non-CA survivors may have influenced the results, however, we deemed the inclusion of these studies as important considering the paucity of data available. The effect of including studies with mixed populations on this review's 
results is difficult to determine without greater examination of the aetiology and secondary consequences of the other non-CA causes of anoxic brain injury. However, Schmidt $e t a l^{2}$ showed a similar change in FIM to two of the studies ${ }^{2033}$ that only included CA survivors (figure 6).

Our primary outcome, HRQoL, is an important outcome in rehabilitation research. ${ }^{7}$ However, the choice of generic or disease-specific HRQoL measures may influence the results as generic measures of HRQoL can be crude with important details lost and large sample sizes required to demonstrate effect. ${ }^{44}{ }^{45}$ In this review, all studies except one ${ }^{34}$ used generic measures of HRQoL.

Another element that potentially influenced our findings may be the standard care received by the RCT control groups. Two ${ }^{21-23}$ of the included RCTs provided educational elements to both the intervention and control groups and in a third ${ }^{46}$ participants could have received cardiac rehabilitation.

The high heterogeneity found between studies, limiting meta-analysis, may be explained by the wide range of physical, neurological and psychological problems suffered by CA survivors. ${ }^{13-6}$ Most CA survivors will have a new or ongoing cardiac condition, ${ }^{1}$ and therefore, be eligible for cardiac rehabilitation. ${ }^{47}$ Neurological rehabilitation has been recommended to meet the 'brain' aspect of CA recovery. ${ }^{3}{ }^{48}$ This can be mild cognitive impairments in self-caring CA survivors ${ }^{49}$ or more severe brain injury needing long-term residential care. ${ }^{3}$ Hence, different CA survivor populations lead naturally to the selection of different rehabilitation interventions and study outcomes.

\section{Implications for future research and clinical practice}

The majority of studies found by this systematic review were observational. Given their potential risk of bias and no control group, we recommend no further observational studies focusing on the question of effectiveness are conducted but instead there is a need for high-quality RCTs comparing rehabilitation interventions for CA survivors to standard care alone. Considering the small population of CA survivors, multicentre RCTs should be considered to achieve a sufficient sample size to determine an effect on specific outcomes. In view of the wide range of potential consequences after $\mathrm{CA}$, future studies might also consider investigating interventions that target a single consequence of CA, for example, fatigue, or whether interventions should be multicomponent. A minimum outcome set for these future rehabilitation RCTs should include those recommended by COSCA (Core Outcome Set for Cardiac Arrest), ${ }^{4}$ HRQoL and neurological function, and consider including diseasespecific outcomes. However, more research is needed to identify outcomes and measurement tools that reflect the range of rehabilitation needs of CA survivors. Agreement on a CA survivors' rehabilitation core outcome set would facilitate subsequent meta-analysis of study results providing a stronger body of evidence on rehabilitation after CA. Further, it is essential future RCTs use agreed reporting guidelines such as CONSORT (Consolidated
Standards of Reporting Trials) ${ }^{50}$ or TIDieR (Template for Intervention Description and Replication $)^{51}$ to detail the complex rehabilitation interventions under investigation. This systematic review has focused primarily on impairment and function outcomes and less on activity and participation. Hence, future systematic reviews on this subject could consider including these outcomes.

Based on the low quality of the body of evidence, clinical rehabilitation guidelines should continue to be consensus based. ${ }^{10}{ }^{11}$ In clinical practice, rehabilitation interventions should be offered based on these consensus-based recommendations with ongoing monitoring of clinical outcomes. The documented secondary physical, neurological and psychological consequences of CA for survivors are so comprehensive ${ }^{13-6}$ that we as clinicians must meet these needs in current clinical practice.

\section{CONCLUSIONS}

Given the overall low quality of evidence, this review cannot determine the effectiveness of rehabilitation interventions for CA survivors on HRQoL, neurological function or other included outcomes, and recommend further high-quality studies are conducted. In the interim, existing clinical guidelines on rehabilitation provision after CA should be followed to meet the high burden of secondary consequences suffered by CA survivors.

\section{Author affiliations}

${ }^{1}$ REHPA, The Danish Knowledge Centre for Rehabilitation and Palliative Care, Odense University Hospital, Odense, Denmark

${ }^{2}$ Department of Occupational- and Physiotherapy, Copenhagen University Hospital, København, Denmark

${ }^{3} 3 \mathrm{MRC} / \mathrm{CSO}$ Social and Public Health Sciences Unit \& Robertson Centre for Biostatistics, Institute of Health and Well Being, University of Glasgow, Glasgow, UK ${ }^{4}$ Department of Physiotherapy and Occupational Therapy, Slagelse Hospital, Slagelse, Sjaelland, Denmark

${ }^{5}$ The Department of Regional Health Research, University of Southern Denmark, Odense, Syddanmark, Denmark

Acknowledgements LHT is currently funded by a grant from the Danish Regions and The Danish Health Confederation through the Development and Research Fund for financial support (project no. 2703) and a grant from Region Zealand, Denmark (Exercise First).

Contributors Conception of study: VLJ, RST, ADZ and LHT. Preparation of protocol: VLJ, JC, RST, ADZ and LHT. Study selection: VLJ, JC, EL and LHT. Data extraction, data analysis and risk of bias assessment: VLJ, JC and LHT. Writing of the manuscript, review and editing: VLJ, JC, EL, RST, ADZ and LHT. The final manuscript was approved by all authors.

Funding This study was supported by infrastructure provided by REHPA, Danish Knowledge Centre for Rehabilitation and Palliative Care, Odense University Hospital which receives funding from the Danish Government. This study is part of a PhD partially funded by a PhD Faculty scholarship (no grant number) from the University of Southern Denmark and a stipendium from the Region of Southern Denmark (19/15041).

Competing interests None declared.

Patient consent for publication Not required.

Provenance and peer review Not commissioned; externally peer reviewed.

Data availability statement Data are available upon reasonable request.

Supplemental material This content has been supplied by the author(s). It has not been vetted by BMJ Publishing Group Limited (BMJ) and may not have been peer-reviewed. Any opinions or recommendations discussed are solely those 
of the author(s) and are not endorsed by BMJ. BMJ disclaims all liability and responsibility arising from any reliance placed on the content. Where the content includes any translated material, BMJ does not warrant the accuracy and reliability of the translations (including but not limited to local regulations, clinical guidelines, terminology, drug names and drug dosages), and is not responsible for any error and/or omissions arising from translation and adaptation or otherwise.

Open access This is an open access article distributed in accordance with the Creative Commons Attribution Non Commercial (CC BY-NC 4.0) license, which permits others to distribute, remix, adapt, build upon this work non-commercially, and license their derivative works on different terms, provided the original work is properly cited, appropriate credit is given, any changes made indicated, and the use is non-commercial. See: http://creativecommons.org/licenses/by-nc/4.0/.

\section{ORCID iD}

Vicky L Joshi http://orcid.org/0000-0003-3524-1990

\section{REFERENCES}

1 Sawyer KN, Camp-Rogers TR, Kotini-Shah P, et al. Sudden cardiac arrest survivorship: a scientific statement from the American heart association. Circulation 2020;141:e654-85.

2 Benjamin EJ, Muntner P, Alonso A, et al. Heart disease and stroke Statistics-2019 update: a report from the American heart association. Circulation 2019;139:E56-28.

3 Boyce LW, Goossens PH. Rehabilitation after cardiac arrest: integration of neurologic and cardiac rehabilitation. Semin Neurol 2017;37:094-102.

4 Haywood K, Whitehead L, Nadkarni VM, et al. COSCA (core outcome set for cardiac arrest) in adults: an Advisory statement from the International liaison Committee on resuscitation. Resuscitation 2018;127:147-63.

5 Wilder Schaaf KP, Artman LK, Peberdy MA, et al. Anxiety, depression, and PTSD following cardiac arrest: a systematic review of the literature. Resuscitation 2013;84:873-7.

6 Elliott VJ, Rodgers DL, Brett SJ. Systematic review of quality of life and other patient-centred outcomes after cardiac arrest survival. Resuscitation 2011;82:247-56.

7 Cantista P, Ceravolo MG, Christodoulou N, et al. White book on physical and rehabilitation medicine (PRM) in Europe. Chapter 1. definitions and concepts of PRM. Eur J Phys Rehabil Med 2018;54:156-65.

8 Anderson L, Taylor RS. Cardiac rehabilitation for people with heart disease: an overview of Cochrane systematic reviews. Cochrane Database Syst Rev 2014;12:CD011273.

9 Turner-Stokes L, Pick A, Nair A, et al. Multi-Disciplinary rehabilitation for acquired brain injury in adults of working age. Cochrane Database Syst Rev 2015;29:CD004170.

10 The Scottish Government. Out-of-Hospital Cardiac Arrest - A Strategy for Scotland, 2015: 1-58.

11 Nolan JP, Soar J, Cariou A, et al. European resuscitation Council and European Society of intensive care medicine 2015 guidelines for post-resuscitation care. Intensive Care Med 2015;41:2039-56.

12 Joshi V, Tang L, Long L. Report on rehabilitation and palliative care in the management of cardiovascular diseases: the evidence and the gaps, 2018. Available: https://hjerteforeningen.dk/wp-content/ uploads/sites/17/2018/02/2018.01-dhf-report-on-rehabilitation-andpalliative-care-final.pdf

13 Tang LH, Zwisler A-D. Rehabilitation after cardiac arrest - we can surely do better! Cardiologisk Forum 2019;30:30-7.

14 Moher D, Liberati A, Tetzlaff J, et al. Preferred reporting items for systematic reviews and meta-analyses: the PRISMA statement. $J$ Clin Epidemiol 2009;62:1006-12.

15 Anderson L, Brown JP, Clark AM, et al. Patient education in the management of coronary heart disease. Cochrane Database Syst Rev 2017;6:CD008895.

16 Sterne JAC, Savović J, Page MJ, et al. Rob 2: a revised tool for assessing risk of bias in randomised trials. BMJ 2019;366:14898.

17 National Institutes of Health. Quality assessment tool for beforeafter (pre-post) studies with no control group. Available: http:// wwwnhlbiningov/health-pro/guidelines/in-develop/cardiovascularrisk-reduction/tools/before-after

18 Matcham F, Scott IC, Rayner L, et al. The impact of rheumatoid arthritis on quality-of-life assessed using the SF-36: a systematic review and meta-analysis. Semin Arthritis Rheum 2014;44:123-30.

19 Guyatt GH, Oxman AD, Schünemann HJ, et al. Grade guidelines: a new series of articles in the Journal of clinical epidemiology. J Clin Epidemiol 2011;64:380-2.
20 Burke DT, Shah MK, Dorvlo ASS, et al. Rehabilitation outcomes of cardiac and non-cardiac anoxic brain injury: a single institution experience. Brain Inj 2005;19:675-80.

21 Cowan MJ, Pike KC, Budzynski HK. Psychosocial nursing therapy following sudden cardiac arrest: impact on two-year survival. Nurs Res 2001;50:68-76.

22 Dougherty CM, Pyper GP, Frasz HA. Description of a nursing intervention program after an implantable cardioverter defibrillator. Heart Lung 2004;33:183-90.

23 Dougherty CM, Thompson EA, Lewis FM. Long-Term outcomes of a telephone intervention after an ICD. Pacing Clin Electrophysiol 2005;28:1157-67.

24 Dougherty CM, Glenny R, Kudenchuk PJ. Aerobic exercise improves fitness and heart rate variability after an implantable cardioverter defibrillator. J Cardiopulm Rehabil Prev 2008;28:307-11.

25 Dougherty CM, Thompson EA, Kudenchuk PJ. Patient plus partner trial: a randomized controlled trial of 2 interventions to improve outcomes after an initial implantable cardioverter-defibrillator. Heart Rhythm 2019;16:453-9.

26 Fertl E, Vass K, Sterz F, et al. Neurological rehabilitation of severely disabled cardiac arrest survivors. Part I. course of post-acute inpatient treatment. Resuscitation 2000;47:231-9.

27 Howell K, Grill E, Klein A-M, et al. Rehabilitation outcome of Anoxicischaemic encephalopathy survivors with prolonged disorders of consciousness. Resuscitation 2013;84:1409-15.

$28 \mathrm{Kim} \mathrm{C}$, Jung $\mathrm{H}$, Choi HE, et al. Cardiac rehabilitation after acute myocardial infarction resuscitated from cardiac arrest. Ann Rehabil Med 2014;38:799-804.

29 Kim YJ, Rogers JC, Raina KD, et al. An intervention for cardiac arrest survivors with chronic fatigue: a feasibility study with preliminary outcomes. Resuscitation 2016;105:109-15.

30 Mion M, Al-Janabi F, Islam S, et al. Care after resuscitation: implementation of the United Kingdom's first dedicated multidisciplinary follow-up program for survivors of out-of-hospital cardiac arrest. Ther Hypothermia Temp Manag 2020;10:53-9.

31 Moulaert VRM, van Heugten CM, Winkens B, et al. Early neurologically-focused follow-up after cardiac arrest improves quality of life at one year: a randomised controlled trial. Int $J$ Cardiol 2015;193:8-16.

32 Schmidt JG, Drew-Cates J, Dombovy ML. Anoxic encephalopathy: outcome after inpatient rehabilitation. Neurorehabil Neural Repair 1997;11:189-95.

33 Shah MK, Carayannopoulos AG, Burke DT, et al. A comparison of functional outcomes in hypoxia and traumatic brain injury: a pilot study. J Neurol Sci 2007;260:95-9.

34 Tazopoulou E, Miljkovitch R, Truelle J-L, et al. Rehabilitation following cerebral anoxia: an assessment of 27 patients. Brain Inj 2016;30:95-103.

35 Joshi VL. Rehabilitation for survivors of cardiac arrest focused on fatigue: U.S. National library of medicine clinical Trials.gov, 2019. Available: https://ClinicalTrials.gov/show/NCT04114773

36 Christensen H. Computer-Assisted Self-training to improve executive function (COMPEX) clinical Trials.gov, 2020. Available: https:// clinicaltrials.gov/ct2/show/NCT042290562021

37 Higgins JPT, Thomas J, Chandler J. Cochrane Handbook for systematic reviews of interventions. version 60: Cochrane, 2019.

38 Beninato M, Gill-Body KM, Salles S, et al. Determination of the minimal clinically important difference in the FIM instrument in patients with stroke. Arch Phys Med Rehabil 2006;87:32-9.

39 Wewege MA, Ahn D, Yu J, et al. High-Intensity interval training for patients with cardiovascular Disease-ls it safe? A systematic review. J Am Heart Assoc 2018;7:e009305.

40 Hannan AL, Hing W, Simas V, et al. High-Intensity interval training versus moderate-intensity continuous training within cardiac rehabilitation: a systematic review and meta-analysis. Open Access $J$ Sports Med 2018;9:1-17.

41 Rognmo Øivind, Moholdt T, Bakken H, et al. Cardiovascular risk of high- versus moderate-intensity aerobic exercise in coronary heart disease patients. Circulation 2012;126:1436-40.

42 Alswyan $\mathrm{AH}$, Liberato ACS, Dougherty CM. A systematic review of exercise training in patients with cardiac implantable devices. $J$ Cardiopulm Rehabil Prev 2018;38:70-84.

43 Richards SH, Anderson L, Jenkinson CE, et al. Psychological interventions for coronary heart disease. Cochrane Database Syst Rev 2017;4:CD002902.

44 Haywood K. Survival and quality of life following a cardiac arrest: capturing what really matters to survivors. Resuscitation 2019;135:221-3.

45 Bohm M, Lilja G, Finnbogadóttir H, et al. Detailed analysis of health-related quality of life after out-of-hospital cardiac arrest. Resuscitation 2019;135:197-204. 
46 Moulaert V, van Heugten C, Winkens B, et al. New psychosocial intervention improves quality of life after cardiac arrest: results of a randomised controlled trial. Resuscitation 2013;84:S1-2.

47 Tang LH, Joshi V, Egholm CL, et al. Are survivors of cardiac arrest provided with standard cardiac rehabilitation? - Results from a national survey of hospitals and municipalities in Denmark. Eur $J$ Cardiovasc Nurs 2021:20:115-23.

48 Maciel CB, Barden MM, Greer DM. Neurologic recovery after cardiac arrest: a multifaceted puzzle requiring comprehensive coordinated care. Curr Treat Options Cardiovasc Med 2017;19:52.
49 Lilja G, Nielsen N, Friberg H, et al. Cognitive function in survivors of out-of-hospital cardiac arrest after target temperature management at $33^{\circ} \mathrm{C}$ versus $36^{\circ} \mathrm{C}$. Circulation $2015 ; 131: 1340-9$.

50 Eldridge SM, Chan CL, Campbell MJ, et al. Consort 2010 statement: extension to randomised pilot and feasibility trials. Pilot Feasibility Stud 2016;2:64.

51 Hoffmann TC, Glasziou PP, Boutron I, et al. Better reporting of interventions: template for intervention description and replication (TIDieR) checklist and guide. BMJ 2014;348:g1687. 